\title{
Genome mining in Trichoderma viride J1-030: discovery and identification of novel sesquiterpene synthase and its products
}

\author{
Xiang Sun, You-Sheng Cai, Yujie Yuan, Guangkai Bian, Ziling Ye, Zixin Deng \\ and Tiangang Liu*
}

\author{
Full Research Paper \\ Address: \\ Key Laboratory of Combinatorial Biosynthesis and Drug Discovery, \\ Ministry of Education and School of Pharmaceutical Sciences, Wuhan \\ University, Wuhan, 430071, P. R. China \\ Email: \\ Tiangang Liu* - liutg@whu.edu.cn \\ * Corresponding author \\ Keywords: \\ genome mining; metabolic engineering; natural products; \\ sesquiterpene synthase; terpenes; Trichoderma viride J1-030
}

\author{
Beilstein J. Org. Chem. 2019, 15, 2052-2058. \\ doi:10.3762/bjoc. 15.202 \\ Received: 25 May 2019 \\ Accepted: 12 August 2019 \\ Published: 28 August 2019 \\ This article is part of the thematic issue "Terpenes". \\ Associate Editor: A. Kirschning \\ (c) 2019 Sun et al.; licensee Beilstein-Institut. \\ License and terms: see end of document.
}

\begin{abstract}
Sesquiterpene synthases in Trichoderma viride have been seldom studied, despite the efficiency of filamentous fungi for terpenoid production. Using the farnesyl diphosphate-overexpressing Saccharomyces cerevisiae platform to produce diverse terpenoids, we herein identified an unknown sesquiterpene synthase from $T$. viride by genome mining and determined the structure of its corresponding products. One new 5/6 bicyclic sesquiterpene and its esterified derivative were characterised by GC-MS and 1D and 2D NMR spectroscopy. To the best of our knowledge, this is the first well-identified sesquiterpene synthase from T. viride to date.
\end{abstract}

\section{Introduction}

Terpenoids represent the most diverse group of natural products, with a wide distribution in microorganisms, plants, insects and various marine invertebrates $[1,2]$. More than 80,000 terpenoids have been identified and characterised [3-5]. These diverse and complex natural products are mostly derived from carbocation cyclisation with linear C5 isoprene precursors, which are catalysed by terpene synthases (TPSs) [6]. TPSs can be classified into three types based on their amino acid sequence. Type I TPSs are metal-dependent enzymes that initiate cyclisation by the elimination of diphosphate groups from precursors and carbocation formation, and type II TPSs initiate the catalytic process by the protonation of an olefinic double bond [7]. The recently reported type III TPSs, UbiA-related TPSs, also catalyse cascade reactions by diphosphate elimination [8]. In addition, each type of TPS is characterised by a unique aspartate-rich motif; most type I TPSs have a DDXXD/E motif and an NSE/DTE motif, whereas type II TPSs have the DXDD motif $[9,10]$.

The $\mathrm{C}_{15}$ sesquiterpenoids constitute a large class of terpenoids with a wide range of industrial and commercial applications, including uses in flavours and perfumes, as bioactive molecules 
in the pharmaceutical industry, and in health care products [11]. Sesquiterpenoids are biosynthesised from the universal linear precursor farnesyl pyrophosphate (FPP) and assembled by FPP synthases, using dimethylallyl diphosphate (DMAPP) and isopentenyl diphosphate (IPP) as substrates. The subsequent elimination of diphosphate from FPP is catalysed by sesquiterpene synthases, with further cyclisation steps to form structurally diverse (poly)cyclic core skeletons [3,12]. A set of postmodification enzymes can transform core sesquiterpene skeletons into different kinds of sesquiterpenoids with potential anticancer, cytotoxic and antibiotic functions [13]. More than 121 skeleton structures derived from the sesquiterpene precursor FPP via sesquiterpene synthase have been described. Nearly $75 \%$ of these structures have at least one six-membered ring; $69 \%$ of these contain five-membered rings, occupying a large portion. Three- and seven-membered ring structures account for just $21 \%$ and $24 \%$ of these structures, respectively. Four (10\%) and eight (7\%) membered ring structures (e.g. asteriscanolide) are seldom found [14]. With the lower costs of gene sequencing, recent developments in genome mining by sequencing and annotation have led to the discovery of a large number of functionally unknown terpene synthases [15-17], generating diverse complex structures and several bioactive products (e.g., $6 \alpha, 9 \alpha, 15$-trihydroxycadinan-4-en-3-one, (+)-3,11,12-trihydroxycalamenene, and (-)-3,10,11,12-tetrahydroxycalamenene) [18].

Filamentous fungi are powerful producers of terpenoid products [19]. Many terpenoids produced by these fungi have recently been characterised; these terpenoids exhibit diverse complex structures and uncommon catalytic mechanisms [20]. However, a limited number of sesquiterpenes have been characterised from a few fungal taxa (e.g., trefolane A and sterhirsutins) [21]. Trichoderma viride is a filamentous fungus that has received considerable attention as an effective biocontrol agent against two fungal pathogens, Fusarium oxysporum f. sp. adzuki and Pythium arrhenomanes, infecting soybean. This fungus is a competent mycoparasite and strong producer of secondary metabolites [22,23]. However, T. viride terpenoids have rarely been studied and the low concentrations of products under natural conditions have limited the pace of research in this field. Metabolic engineering makes the overproduction of different terpenoids from $T$. viride possible $[21,24]$. To increase the discovery efficiency of terpenoid products, heterologous expression of various sources of terpene synthases in Escherichia coli and Saccharomyces cerevisiae is a feasible approach $[25,26]$.

In this study, a combination of genome mining and metabolic engineering was used for sesquiterpenoid discovery, utilizing farnesyl diphosphate-overexpressing S. cerevisiae as a platform
(Figure 1). By the heterologous expression of predicted terpene synthases from the genome of $T$. viride, an unknown sesquiterpene synthase was identified and characterised. Furthermore, a new compound produced by this enzyme and its esterified product were detected and characterised by GC-MS and 1D and 2D NMR, revealing a 5/6 bicyclic sesquiterpene and its C-11 esterified structure. Based on a literature search, to our knowledge, this is the first report of the characterisation of a sesquiterpene synthase in $T$. viride. In addition, this study demonstrates the effectiveness of the combination of genome mining and heterologous expression of predicted terpene synthases for detecting unknown terpenoids from rarely studied fungi.

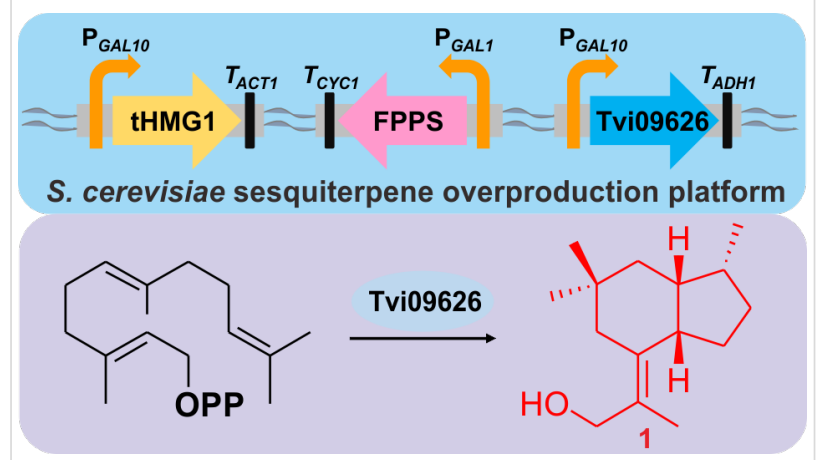

Figure 1: Schematic diagram of the $S$. cerevisiae sesquiterpene overproduction platform and the products of Tvi09626.

\section{Results and Discussion}

\section{Prediction and analysis of terpene synthase genes in $T$. viride $\mathrm{J} 1-030$}

Through genome sequencing of $T$. viride $\mathrm{J} 1-030$ and prediction of the potential terpene synthases in J1-030 genome, gene Tvi09626 was selected and the following bioinformatics analysis of the function of this unidentified terpene synthase was performed. A protein blast search against the NCBI database was performed with Tvi09626, revealing sequence identities of $89.66 \%$ and $85.23 \%$ with the enzymes from the strain $T$. virens Gv29-8 [27] and T. reesei QM6a [28], respectively, with only predicted functions. Thereafter, an amino acid sequence alignment with several known terpene synthases showed that Tvi09626 had the typical highly conserved ${ }^{128} \mathbf{D D x x D / E}$ aspartate-rich motif, ${ }^{276}$ NSE/DTE triad, ${ }^{366} \mathbf{R Y}$ dimer and ${ }^{230} \mathbf{R}$ monomer (Figure S1, Supporting Information File 1) [29-31]. Furthermore, in a phylogenetic analysis (Figure 2), Tvi09626 belonged to Clade $\mathrm{V}$ of Class I terpene synthases. In previous studies, terpene synthases have been studied in the genus Trichoderma, such as trichodiene synthase homologous gene isolation and characterisation in T. harzianum [32] and functional identification of terpene synthase vir4 in T. virens [33]. However, owing to the general lack of previous studies of 


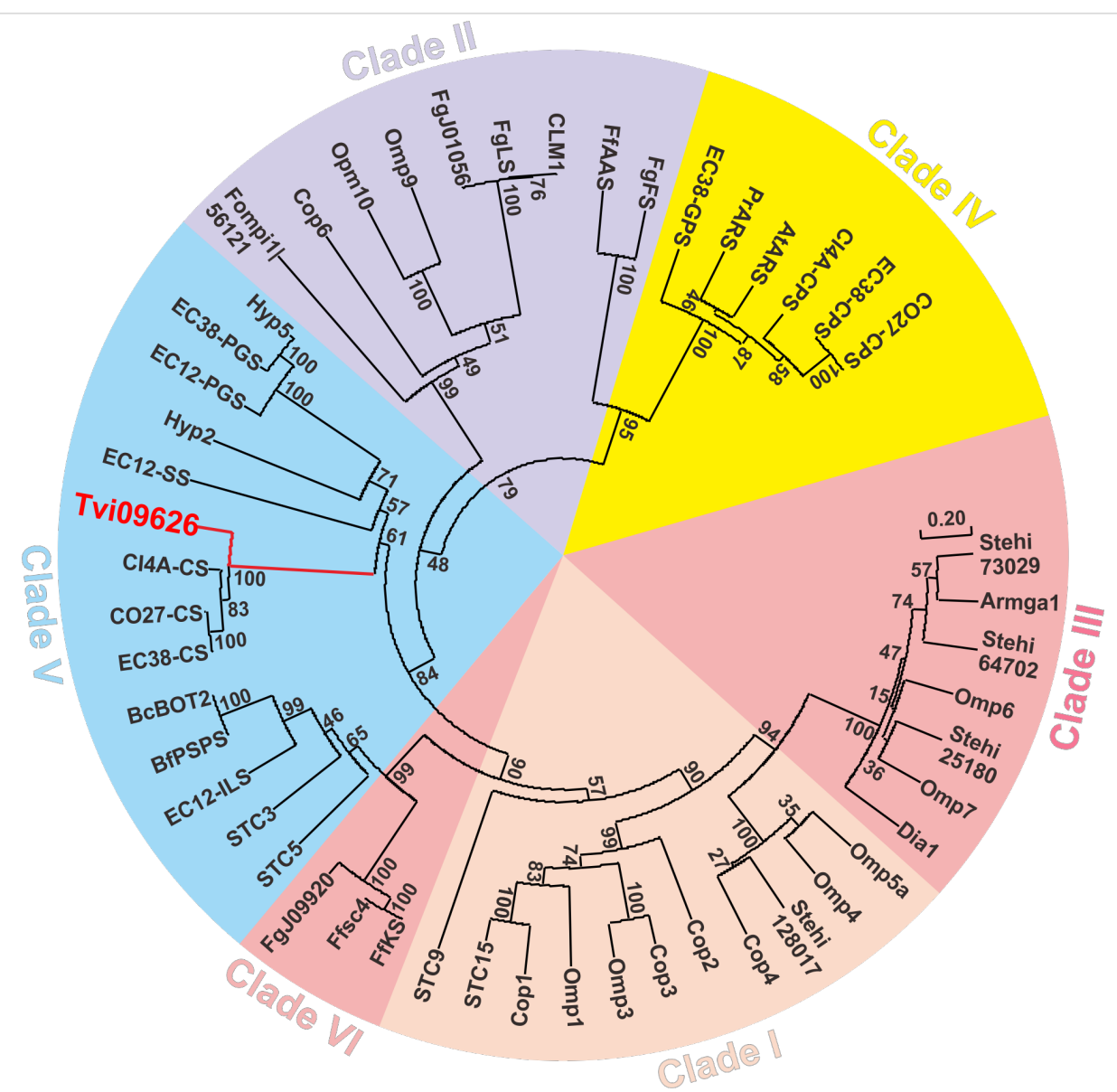

Figure 2: Phylogenetic analysis of Tvi09626 with other characterised terpene synthases. Six clades are marked with different colours and Tvi09626 is labelled in red in Clade V. Percentages indicate branch support based on 1,000 bootstrap replicates.

terpene synthases in T. viride, Tvi09626 is the first terpene synthase well-identified with products characterised in $T$. viride.

\section{In vitro analysis of Tvi09626 function}

To confirm the function of the candidate enzyme, the DNA sequence of Tvi09626 was amplified by touchdown PCR from the T. viride genome. The gene fragment was cloned into a pET28a (+) vector to construct the plasmid pXS222. Next, pXS222 was transformed into BL21 to overexpress and purify Tvi09626 (Figure S2, Supporting Information File 1). The substrates GPP, FPP and GGPP were incubated with the protein individually and the products were detected and analysed by gas chromatography/mass spectrometry (GC-MS) [30,34]. In vitro assays clearly showed that Tvi09626 could use FPP as its only substrate to produce compound 1 (Figure 3 and Figure S3, Supporting Information File 1).

\section{Heterologous expression of Tvi09626 in S. cerevisiae}

To further verify the function of the putative terpene synthase, a metabolic engineering strategy was used to reconstruct an FPP

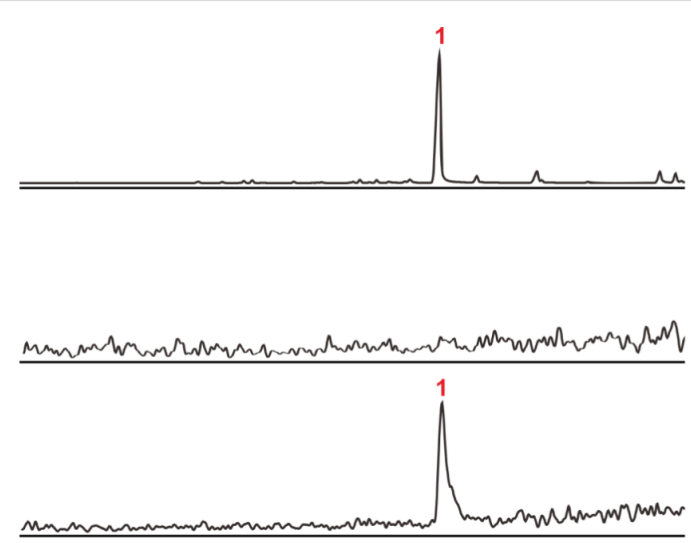

(I)

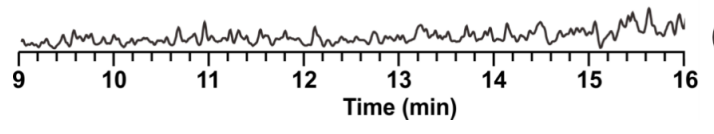

Figure 3: GC-MS chromatogram of products in vivo (I), in yeast YZL141 (II), in vitro Tvi09626 with FPP (III), and boiled Tvi09626 with FPP (IV). 
overproduction platform in S. cerevisiae in order to obtain sufficient quantities of the products of Tvi09626 for chemical structural characterisation. S. cerevisiae YZL141, engineered previously [21], was used owing to its ability to provide enough IPP, DMAPP, and FPP for the production of terpenoids (Figure 1) After $72 \mathrm{~h}$ of shaken-flask fermentation, the strain was extracted with hexane/ethyl acetate $(4: 1)$, pre-separated by silica gel column chromatography, and detected by GC-MS Similar to the in vitro assay results, compound $\mathbf{1}$ was the final product (Figure 4). Interestingly, during the extraction process, compound 2 was detected at a retention time of $14.53 \mathrm{~min}$ and identified as esterified compound $\mathbf{1}$ (Figure 4 and Table S4, Supporting Information File 1). Using the metabolic engineering strategy, the product of Tvi09626 was efficiently enriched via an abundant FPP supply.

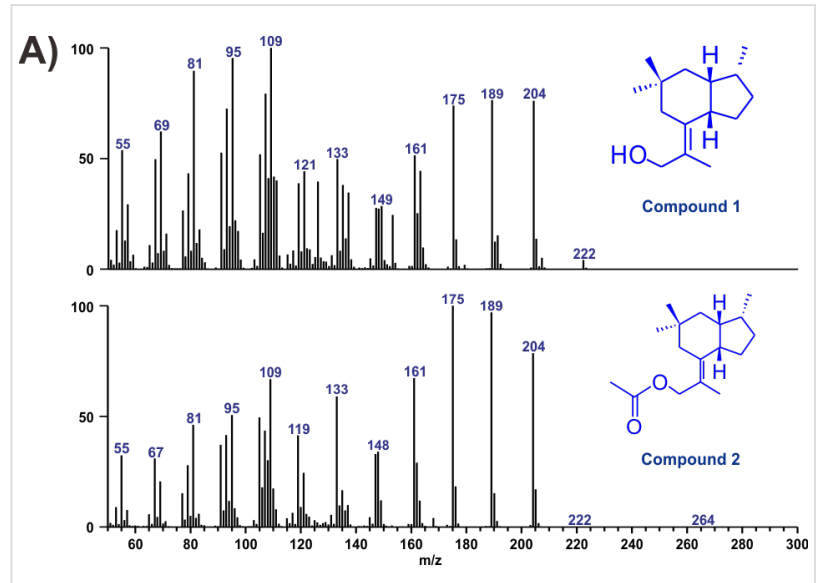

B)
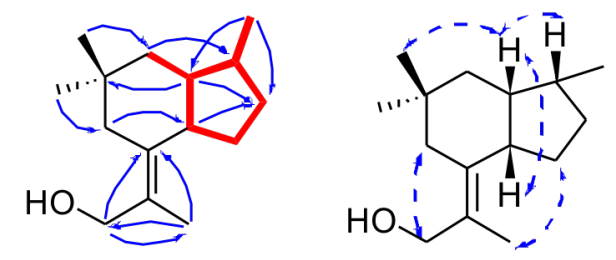

\section{${ }^{1} \mathrm{H}^{-1} \mathrm{H}$ COSY $-\mathrm{HMBC} \longrightarrow$ NOESY,-}

Figure 4: Characterisation of Tvi09626 products. (A) Mass spectra of compound 1 at $t_{\mathrm{R}}=13.46 \mathrm{~min}$ with $\mathrm{m} / \mathrm{z} 222$ and compound 2 at $t_{\mathrm{R}}=14.53 \mathrm{~min}$ with $\mathrm{m} / \mathrm{z} 264$. (B) COSY, HMBC and NOESY correlations for compound 1 .

\section{Detection and characterisation of Tvi09626 products}

By semi-preparative high-performance liquid chromatography (HPLC), we purified compound $\mathbf{1}$ and compound 2 (23.1 mg and $13.2 \mathrm{mg}$, respectively). The structures of the two new compounds were characterised by $1 \mathrm{D}$ and 2D NMR spectroscopy (Table 1, Table S4, and Figures S4-S15, Supporting Information File 1).
Table 1: ${ }^{1} \mathrm{H}$ NMR $\left(400 \mathrm{MHz}, \mathrm{CDCl}_{3}\right)$ and ${ }^{13} \mathrm{C}$ NMR $(100 \mathrm{MHz})$ data for compound 1 in $\mathrm{CDCl}_{3}$.

\begin{tabular}{|c|c|c|}
\hline Position & $\delta_{C}$ & $\delta_{H}$ \\
\hline 1 & 45.2 & $1.68(\mathrm{dd}, 8.2,4.3 \mathrm{~Hz}, 1 \mathrm{H})$ \\
\hline 2 & 40.6 & $\begin{array}{l}1.38(\mathrm{ddd}, J=12.8,3.9,1.6 \mathrm{~Hz}, 1 \mathrm{H}) \\
1.16(\mathrm{t}, J=12.9 \mathrm{~Hz}, 1 \mathrm{H})\end{array}$ \\
\hline 3 & 33 & - \\
\hline 4 & 43.8 & $\begin{array}{l}2.35(\mathrm{dd}, J=13.8,1.4 \mathrm{~Hz}, 1 \mathrm{H}), 1.60(\mathrm{~d}, \\
J=13.8 \mathrm{~Hz}, 1 \mathrm{H})\end{array}$ \\
\hline 5 & 137.4 & - \\
\hline 6 & 47.6 & $1.96(\mathrm{dd}, J=12.3,6.1 \mathrm{~Hz}, 1 \mathrm{H})$ \\
\hline 7 & 30.9 & $2.10(\mathrm{~m}, 1 \mathrm{H}), 1.60(\mathrm{~m}, 1 \mathrm{H})$ \\
\hline 8 & 33.3 & $2.07(\mathrm{~m}, 1 \mathrm{H}), 1.07(\mathrm{~m}, 1 \mathrm{H})$ \\
\hline 9 & 31.6 & $1.99(\mathrm{~m}, 1 \mathrm{H})$ \\
\hline 10 & 126.5 & - \\
\hline 11 & 65.2 & $\begin{array}{l}4.18(\mathrm{~d}, J=11.6 \mathrm{~Hz}, 1 \mathrm{H}), 3.97(\mathrm{~d} \\
J=9.8 \mathrm{~Hz}, 1 \mathrm{H})\end{array}$ \\
\hline 12 & 17.85 & $1.87(\mathrm{t}, J=1.2 \mathrm{~Hz}, 3 \mathrm{H})$ \\
\hline 13 & 32 & $0.96(\mathrm{~s}, 3 \mathrm{H})$ \\
\hline 14 & 26.1 & $0.83(\mathrm{~s}, 3 \mathrm{H})$ \\
\hline 15 & 17.78 & $0.80(\mathrm{~d}, J=7.0 \mathrm{~Hz}, 3 \mathrm{H})$ \\
\hline 16 & - & $3.47(\mathrm{~s}, 1 \mathrm{H})$ \\
\hline
\end{tabular}

Compound 1 was a new compound with a known skeleton [35], isolated as a white powder. ${ }^{1} \mathrm{H}$ and ${ }^{13} \mathrm{C}$ NMR data showed four methyl groups at $\delta_{\mathrm{H}} 1.87\left(\mathrm{t}, J=1.2 \mathrm{~Hz}, 3 \mathrm{H}\right.$,), $\delta_{\mathrm{H}} 0.96(\mathrm{~s}, 3 \mathrm{H})$, $\delta_{\mathrm{H}} 0.83(\mathrm{~s}, 3 \mathrm{H})$, and $\delta_{\mathrm{H}} 0.80(\mathrm{~d}, J=7.0 \mathrm{~Hz}, 3 \mathrm{H})$. Five methylenes were detected, including an oxygenated one at $\delta_{\mathrm{H}} 4.18(\mathrm{~d}$, $J=11.6 \mathrm{~Hz}, 1 \mathrm{H}), 3.97(\mathrm{~d}, J=9.8 \mathrm{~Hz}, 1 \mathrm{H})$, as well as three methines and three quaternary carbons including a double bond at $\delta_{\mathrm{C}} 137.4$ (C-5), 126.5 (C-10). The 2D NMR data indicated that compound $\mathbf{1}$ is a $5 / 6$ bicyclic sesquiterpene with the molecular formula $\mathrm{C}_{15} \mathrm{H}_{26} \mathrm{O}$ (Figure 1). Interestingly, compound $\mathbf{1}$ contained a quaternary carbon with two methyl groups, which is uncommon for the cyclization mechanism of sesquiterpenoids and needs further investigation.

Compound 2 was purified as a white powder. ${ }^{1} \mathrm{H}$ and ${ }^{13} \mathrm{C}$ NMR data showed chemical shifts of five methyl groups at $\delta_{\mathrm{H}} 1.83(\mathrm{t}$, $J=1.2 \mathrm{~Hz}, 3 \mathrm{H}), \delta_{\mathrm{H}} 0.96(\mathrm{~s}, 3 \mathrm{H}), \delta_{\mathrm{H}} 0.82(\mathrm{~s}, 3 \mathrm{H}), \delta_{\mathrm{H}} 0.80(\mathrm{~d}$, $J=7.0 \mathrm{~Hz}, 3 \mathrm{H})$, and $\delta_{\mathrm{H}} 2.06(\mathrm{~s}, 3 \mathrm{H})$. Five methylenes were identified, including an esterified group at $\mathrm{C}-11$ with a resonance of $\delta_{\mathrm{H}} 4.64(\mathrm{~d}, J=11.6 \mathrm{~Hz} 1 \mathrm{H}), 4.46(\mathrm{~d}, J=11.6 \mathrm{~Hz}, 1 \mathrm{H})$, three methines, and three quaternary carbons including a double bond at $\delta_{\mathrm{C}} 140.37$ (C-5), 122.04 (C-10). Compared with 2D NMR information of compound $\mathbf{1}$, compound 2 was a C-11 esterified 1 with the molecular formula $\mathrm{C}_{17} \mathrm{H}_{28} \mathrm{O}_{2}$ (Table $\mathrm{S} 4$, Supporting Information File 1), which may represent the esterification reaction during the extraction process.

The 5/6 bicyclic sesquiterpene identified and characterised in this study was a brasilane-type sesquiterpenoid; this sesquiter- 
penoid type is typically isolated from cultures of the basidiomycete Coltricia sideroides in combination with its two new alkane derivatives colisiderin $\mathrm{A}$ and $(7 E, 9 E)$-undeca-7,9-diene2,4,5-triol [35] and from the organic extract of the red alga Laurencia obtusa [36]. However, to the best of our knowledge, ours is the first report of these brasilane-type sesquiterpenes obtained via biosynthetic genes.

\section{Metal ion dependency of Tvi09626 and its kinetics}

As reported previously, most terpene synthases are active in the presence of $\mathrm{Mg}^{2+}$ ions $[8,37]$. To test the $\mathrm{Mg}^{2+}$ dependency of Tvi09626, an in vitro assay was performed. The GC-MS analysis showed that in the presence of $\mathrm{Mg}^{2+}$, compound $\mathbf{1}$ can be obtained, whereas without $\mathrm{Mg}^{2+}$ or added EDTA $(2.5 \mathrm{mM})$, compound 1 cannot be detected (Figure 5). This assay demonstrated that Tvi09626 was a $\mathrm{Mg}^{2+}$-dependent sesquiterpene synthase. In a kinetics analysis, the turnover rate $\left(k_{\mathrm{cat}}\right)$ of the enzyme with FPP was $(15 \pm 0.3) \times 10^{-2}$, which is similar to those of omp6 and omp7. Its substrate affinity $\left(K_{\mathrm{m}}\right)$ was $(0.44 \pm 0.11) \times 10^{-6}$, one-tenth that of omp6 and nearly a quarter that of omp7. The catalytic efficiency $\left(k_{\mathrm{cat}} / K_{\mathrm{m}}\right)$ of Tvi09626 was $(35.32 \pm 0.57) \times 10^{3}$, higher than that of omp6 and lower than that of omp7 $[21,38]$.

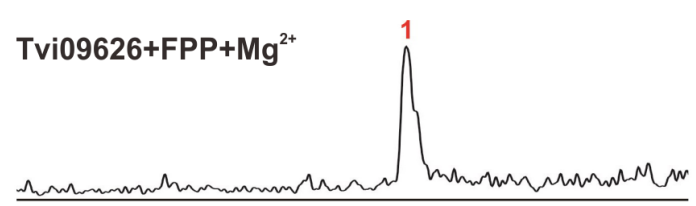

(I)

\section{Tvi09626+FPP+EDTA}

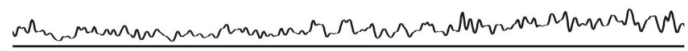

(II)

\section{Control+FPP+ $\mathrm{Mg}^{2+}$}

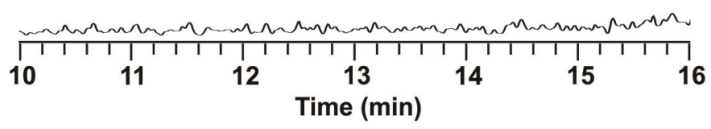

(III)

Figure 5: GC-MS chromatogram for the metal ion dependency assay.

\section{Conclusion}

In conclusion, we identified a novel sesquiterpene synthase, Tvi09626, from $T$. viride using a strong sesquiterpene overproduction platform with $S$. cerevisiae YZL141; it is the first biochemically identified and characterised sesquiterpene synthase from this filamentous fungus. In an analysis of its relative structure, the product of this enzyme was characterised as a
5/6 bicyclic sesquiterpene compound 1 oxygenated at C-11. Interestingly, esterified compound $\mathbf{1}$ was isolated during the product extraction process, suggesting an esterification reaction. It contained a quaternary carbon with two methyl groups, which is uncommon of the cyclization mechanism of sesquiterpenoids and needs to be studied in the future. To the best of our knowledge, this study reports the first use of a biosynthetic gene to obtain a brasilane-type sesquiterpene.

\section{Supporting Information}

\section{Supporting Information File 1}

Experimental part and supplementary figures and tables.

[https://www.beilstein-journals.org/bjoc/content/ supplementary/1860-5397-15-202-S1.pdf]

\section{Acknowledgements}

We thank Dr. You-Sheng Cai (Wuhan University) for suggestions regarding structural characterisation. This work was financially supported by funding from the National Key R\&D Program of China (2018YFA0900400), the Medical Science Advancement Program (Clinical Medicine) of Wuhan University, the state Key Laboratory of Microbial Metabolism, Shanghai Jiao Tong University (grant MMLKF 18-12) and the National Natural Science Foundation of China (31800032).

\section{ORCID ${ }^{\circledR}$ iDs}

Xiang Sun - https://orcid.org/0000-0001-6703-0413

Tiangang Liu - https://orcid.org/0000-0001-8087-0345

\section{References}

1. Bian, G. K.; Ma, T.; Liu, T. G. Methods Enzymol. 2018, 608, 97-129. doi:10.1016/bs.mie.2018.04.025

2. Huber, T.; Weisheit, L.; Magauer, T. Beilstein J. Org. Chem. 2015, 11, 2521-2539. doi:10.3762/bjoc.11.273

3. Christianson, D. W. Chem. Rev. 2017, 117, 11570-11648. doi:10.1021/acs.chemrev.7b00287

4. Pemberton, T. A.; Chen, M.; Harris, G. G.; Chou, W. K. W.; Duan, L.; Köksal, M.; Genshaft, A. S.; Cane, D. E.; Christianson, D. W. Biochemistry 2017, 56, 2010-2023. doi:10.1021/acs.biochem.7b00137

5. Lauterbach, L.; Rinkel, J.; Dickschat, J. S. Angew. Chem., Int. Ed. 2018, 57, 8280-8283. doi:10.1002/anie.201803800

6. Huang, A. C.; Hong, Y. J.; Bond, A. D.; Tantillo, D. J.; Osbourn, A. Angew. Chem., Int. Ed. 2018, 57, 1291-1295. doi:10.1002/anie.201711444

7. Bian, G.; Rinkel, J.; Wang, Z.; Lauterbach, L.; Hou, A.; Yuan, Y.; Deng, Z.; Liu, T.; Dickschat, J. S. Angew. Chem., Int. Ed. 2018, 57, 15887-15890. doi:10.1002/anie.201809954

8. Yang, Y.-I.; Zhang, S.; Ma, K.; Xu, Y.; Tao, Q.; Chen, Y.; Chen, J.; Guo, S.; Ren, J.; Wang, W.; Tao, Y.; Yin, W.-B.; Liu, H. Angew. Chem., Int. Ed. 2017, 56, 4749-4752. doi:10.1002/anie.201700565 
9. Köksal, M.; Jin, Y.; Coates, R. M.; Croteau, R.; Christianson, D. W. Nature 2011, 469, 116-120. doi:10.1038/nature09628

10. Rabe, P.; Rinkel, J.; Nubbemeyer, B.; Köllner, T. G.; Chen, F.; Dickschat, J. S. Angew. Chem., Int. Ed. 2016, 55, 15420-15423. doi:10.1002/anie.201608971

11. Peng, B.; Plan, M. R.; Chrysanthopoulos, P.; Hodson, M. P.; Nielsen, L. K.; Vickers, C. E. Metab. Eng. 2017, 39, 209-219. doi:10.1016/j.ymben.2016.12.003

12. Matsuda, Y.; Mitsuhashi, T.; Quan, Z.; Abe, I. Org. Lett. 2015, 17 , 4644-4647. doi:10.1021/acs.orglett.5b02404

13. Kim, D.; Lee, E.; Lee, J.; Leutou, A.; Shin, Y.-H.; Choi, B.; Hwang, J.; Hahn, D.; Choi, H.; Chin, J.; Cho, S.; Hong, Y.; Ko, J.; Seong, C.; Maloney, K.; Oh, D.-C.; Yang, I.; Hwang, H.; Nam, S.-J. Mar. Drugs 2018, 16, 130. doi:10.3390/md16040130

14. Klapschinski, T. A.; Rabe, P.; Dickschat, J. S. Angew. Chem., Int. Ed. 2016, 55, 10141-10144. doi:10.1002/anie.201605425

15. Ye, Y.; Minami, A.; Mandi, A.; Liu, C.; Taniguchi, T.; Kuzuyama, T.; Monde, K.; Gomi, K.; Oikawa, H. J. Am. Chem. Soc. 2015, 137, 11846-11853. doi:10.1021/jacs.5b08319

16. Nakano, C.; Kudo, F.; Eguchi, T.; Ohnishi, Y. ChemBioChem 2011, 12 , 2271-2275. doi:10.1002/cbic.201100418

17. Hu, Y.; Chou, W. K. W.; Hopson, R.; Cane, D. E. Chem. Biol. 2011, 18, 32-37. doi:10.1016/j.chembiol.2010.11.008

18. Cao, L.; Shehla, N.; Tasneem, S.; Cao, M.; Sheng, W.; Jian, Y.; Li, B.; Peng, C.; Choudhary, M. I.; Atta-ur-Rahman; Liao, D.-f.; Wang, W. Molecules 2019, 24, 1664. doi:10.3390/molecules24091664

19. Yan, Y.; Liu, Q.; Zang, X.; Yuan, S.; Bat-Erdene, U.; Nguyen, C.; Gan, J.; Zhou, J.; Jacobsen, S. E.; Tang, Y. Nature 2018, 559, 415-418. doi:10.1038/s41586-018-0319-4

20. Minami, A.; Ozaki, T.; Liu, C.; Oikawa, H. Nat. Prod. Rep. 2018, 35, 1330-1346. doi:10.1039/c8np00026c

21. Bian, G.; Hou, A.; Yuan, Y.; Hu, B.; Cheng, S.; Ye, Z.; Di, Y.; Deng, Z.; Liu, T. Org. Lett. 2018, 20, 1626-1629. doi:10.1021/acs.orglett.8b00366

22. Mannina, L.; Segre, A. L.; Ritieni, A.; Fogliano, V.; Vinale, F.; Randazzo, G.; Maddau, L.; Bottalico, A. Tetrahedron 1997, 53, 3135-3144. doi:10.1016/s0040-4020(97)00024-0

23. John, R. P.; Tyagi, R. D.; Prévost, D.; Brar, S. K.; Pouleur, S.; Surampalli, R. Y. Crop Prot. 2010, 29, 1452-1459. doi:10.1016/j.cropro.2010.08.004

24. Bian, G.; Deng, Z.; Liu, T. Curr. Opin. Biotechnol. 2017, 48, 234-241. doi:10.1016/j.copbio.2017.07.002

25. Peng, B.; Nielsen, L. K.; Kampranis, S. C.; Vickers, C. E. Metab. Eng. 2018, 47, 83-93. doi:10.1016/j.ymben.2018.02.005

26. Yap, H.-Y. Y.; Muria-Gonzalez, M. J.; Kong, B.-H.; Stubbs, K. A.; Tan, C.-S.; Ng, S.-T.; Tan, N.-H.; Solomon, P. S.; Fung, S.-Y.; Chooi, Y.-H. Microb. Cell Fact. 2017, 16, 103. doi:10.1186/s12934-017-0713-x
27. Kubicek, C. P.; Herrera-Estrella, A.; Seidl-Seiboth, V.; Martinez, D. A.; Druzhinina, I. S.; Thon, M.; Zeilinger, S.; Casas-Flores, S.; Horwitz, B. A.; Mukherjee, P. K.; Mukherjee, M.; Kredics, L.; Alcaraz, L. D.; Aerts, A.; Antal, Z.; Atanasova, L.; Cervantes-Badillo, M. G.; Challacombe, J.; Chertkov, O.; McCluskey, K.; Coulpier, F.; Deshpande, N.; von Döhren, H.; Ebbole, D. J.; Esquivel-Naranjo, E. U.; Fekete, E.; Flipphi, M.; Glaser, F.; Gómez-Rodríguez, E. Y.; Gruber, S.; Han, C.; Henrissat, B.; Hermosa, R.; Hernández-Oñate, M.; Karaffa, L.; Kosti, I.; Le Crom, S.; Lindquist, E.; Lucas, S.; Lübeck, M.; Lübeck, P. S.; Margeot, A.; Metz, B.; Misra, M.; Nevalainen, H.; Omann, M.; Packer, N.; Perrone, G.; Uresti-Rivera, E. E.; Salamov, A.; Schmoll, M.; Seiboth, B.; Shapiro, H.; Sukno, S.; Tamayo-Ramos, J. A.; Tisch, D.; Wiest, A.; Wilkinson, H. H.; Zhang, M.; Coutinho, P. M.; Kenerley, C. M.; Monte, E.; Baker, S. E.; Grigoriev, I. V. Genome Biol. 2011, 12, R40. doi:10.1186/gb-2011-12-4-r40

28. Martinez, D.; Berka, R. M.; Henrissat, B.; Saloheimo, M.; Arvas, M.; Baker, S. E.; Chapman, J.; Chertkov, O.; Coutinho, P. M.; Cullen, D.; Danchin, E. G. J.; Grigoriev, I. V.; Harris, P.; Jackson, M.; Kubicek, C. P.; Han, C. S.; Ho, I.; Larrondo, L. F.; de Leon, A. L.; Magnuson, J. K.; Merino, S.; Misra, M.; Nelson, B.; Putnam, N.; Robbertse, B.; Salamov, A. A.; Schmoll, M.; Terry, A.; Thayer, N.; Westerholm-Parvinen, A.; Schoch, C. L.; Yao, J.; Barabote, R.; Nelson, M. A.; Detter, C.; Bruce, D.; Kuske, C. R.; Xie, G.; Richardson, P.; Rokhsar, D. S.; Lucas, S. M.; Rubin, E. M.; Dunn-Coleman, N.; Ward, M.; Brettin, T. S. Nat. Biotechnol. 2008, 26 , 553-560. doi:10.1038/nbt1403

29. Yuan, Y.; Litzenburger, M.; Cheng, S.; Bian, G.; Hu, B.; Yan, P.; Cai, Y.; Deng, Z.; Bernhardt, R.; Liu, T. ChemBioChem 2019, 20 , 677-682. doi:10.1002/cbic.201800670

30. Burkhardt, I.; Siemon, T.; Henrot, M.; Studt, L.; Rösler, S.; Tudzynski, B.; Christmann, M.; Dickschat, J. S. Angew. Chem., Int. Ed. 2016, 55, 8748-8751. doi:10.1002/anie.201603782

31. Burkhardt, I.; Kreuzenbeck, N. B.; Beemelmanns, C.; Dickschat, J. S. Org. Biomol. Chem. 2019, 17, 3348-3355. doi:10.1039/c8ob02744g

32. Gallo, A.; Mulè, G.; Favilla, M.; Altomare, C. Physiol. Mol. Plant Pathol. 2004, 65, 11-20. doi:10.1016/j.pmpp.2004.11.005

33. Crutcher, F. K.; Parich, A.; Schuhmacher, R.; Mukherjee, P. K.; Zeilinger, S.; Kenerley, C. M. Fungal Genet. Biol. 2013, 56, 67-77. doi:10.1016/j.fgb.2013.05.003

34. Zhu, F.; Zhong, X.; Hu, M.; Lu, L.; Deng, Z.; Liu, T. Biotechnol. Bioeng. 2014, 111, 1396-1405. doi:10.1002/bit.25198

35. Hu, D.-B.; Zhang, S.; He, J.-B.; Dong, Z.-J.; Li, Z.-H.; Feng, T.; Liu, J.-K. Fitoterapia 2015, 104, 50-54. doi:10.1016/j.fitote.2015.05.009

36. Iliopoulou, D.; Vagias, C.; Galanakis, D.; Argyropoulos, D.; Roussis, V. Org. Lett. 2002, 4, 3263-3266. doi:10.1021/ol026506z

37. Takino, J.; Kozaki, T.; Sato, Y.; Liu, C.; Ozaki, T.; Minami, A.; Oikawa, H. J. Am. Chem. Soc. 2018, 140, 12392-12395. doi:10.1021/jacs.8b08925

38. Wawrzyn, G. T.; Quin, M. B.; Choudhary, S.; López-Gallego, F.; Schmidt-Dannert, C. Chem. Biol. 2012, 19, 772-783. doi:10.1016/j.chembiol.2012.05.012 


\section{License and Terms}

This is an Open Access article under the terms of the Creative Commons Attribution License (http://creativecommons.org/licenses/by/4.0). Please note that the reuse, redistribution and reproduction in particular requires that the authors and source are credited.

The license is subject to the Beilstein Journal of Organic Chemistry terms and conditions:

(https://www.beilstein-journals.org/bjoc)

The definitive version of this article is the electronic one which can be found at:

$\underline{\text { doi:10.3762/bjoc. } 15.202}$ 